\title{
Publisher Correction: Low genetic variation is associated with low mutation rate in the giant duckweed
}

\author{
Shuqing Xu (1) ${ }^{1}$, Jessica Stapley (10 ${ }^{2}$, Saskia Gablenz ${ }^{3}$, Justin Boyer ${ }^{3}$, Klaus J. Appenroth ${ }^{4}$, K. Sowjanya Sree ${ }^{5}$, \\ Jonathan Gershenzon ${ }^{3}$, Alex Widmer (1) ${ }^{6}$ \& Meret Huber (iD ${ }^{3,7}$
}

Correction to: Nature Communications https://doi.org/10.1038/s41467-019-09235-5, published online 18 March 2019

The original HTML version of this Article had an incorrect Published online date of 20 March 2019; it should have been 18 March 2019. This has been corrected in the HTML version of the Article. The PDF version was correct from the time of publication.

Published online: 16 April 2019

\begin{abstract}
(c) (i) Open Access This article is licensed under a Creative Commons Attribution 4.0 International License, which permits use, sharing, adaptation, distribution and reproduction in any medium or format, as long as you give appropriate credit to the original author(s) and the source, provide a link to the Creative Commons license, and indicate if changes were made. The images or other third party material in this article are included in the article's Creative Commons license, unless indicated otherwise in a credit line to the material. If material is not included in the article's Creative Commons license and your intended use is not permitted by statutory regulation or exceeds the permitted use, you will need to obtain permission directly from the copyright holder. To view a copy of this license, visit http://creativecommons.org/licenses/by/4.0/.
\end{abstract}

(C) The Author(s) 2019

\footnotetext{
${ }^{1}$ Institute for Evolution and Biodiversity, University of Münster, Hüfferstrasse 1, 48149 Münster, Germany. ${ }^{2}$ Center for Adaptation to a Changing Environment, ETH Zurich, Universitätstrasse 16, 8092 Zürich, Switzerland. ${ }^{3}$ Department of Biochemistry, Max Planck Institute for Chemical Ecology, HansKnöll-Strasse 8, 07745 Jena, Germany. ${ }^{4}$ Matthias-Schleiden-Institute, Plant Physiology, Friedrich Schiller University of Jena, Dornburgerstraße 159,07743 Jena, Germany. ${ }^{5}$ Department of Environmental Science, Central University of Kerala, Periye 671316, India. ${ }^{6}$ Institute of Integrative Biology, ETH Zurich, Universitätstrasse 16, 8092 Zürich, Switzerland. ${ }^{7}$ Institute of Plant Biology and Biotechnology, University of Münster, Schlossplatz 7, 48143 Münster, Germany. Correspondence and requests for materials should be addressed to S.X. (email: shuqing.xu@uni-muenster.de) or to M.H. (email: huberm@uni-muenster.de)
} 